\title{
EDITORIAL
}

\section{ON PARETO DISTRIBUTIONS AND RATING: \\ A PRIZE AWARD COMPETITION}

The ASTIN Bulletin has always stressed the importance of discussions on actuarial matters across the boundaries often separating academics and practitioners. Our Society has been extremely fortunate to have among its members actuarial personalities who have been/still are instrumental in just doing that. One prominent actuary whose contributions have livened up many an ASTIN meeting is Gunnar Benktander. Some of you no doubt remember his most interesting historical votum on the occasion of the XXVII ASTIN Colloquium in Copenhagen, 1996 (see the ASTIN Bulletin, Editorial, 27 (2)).

Over the recent years, various of the ideas originating from Benktander's work have resurfaced in fields like (re)insurance rating and risk management. The latter especially through linking the modelling of rare events to the fundamental properties of Pareto type distributions, in particular using the mean excess function. See for instance [2] and [3]. More recently, the mean excess (residual life) function reappeared as a key tool in the general area of integrated risk management; see [1]. Its resurfacing in the latter case has led to the creation of the notion of "Insurance Analytics", a body of actuarial techniques within financial risk management. In view of this revival, Gunnar Benktander has decided to offer a prize for a contribution on this general area of actuarial research; see the details below.

The signature date, February 6, 1999 is no coincidence: indeed, on that date Gunnar Benktander celebrated his 80th birthday. On behalf of all ASTIN readers, many congratulations!

PAUl EMBRECHTS

Editor of the ASTIN Bulletin

\section{REFERENCES}

1 Artzner, P., F. Delbaen, J.-M. Eber and D. Heath (1999). Coherent measures of risk. To appear in Mathematical Finance.

2 Embrechts, P., C. Klüppelberg and T. MikosCh (1997). Modelling Extremal Events for Insurance and Finance, Springer-Verlag, Berlin.

3 Klugman, S.A., H.H. Panjer and G.E. Willmot (1998). Loss models. From Data to Decisions, Wiley, New York. 


\section{Prize Award Competition}

At the combined ASTIN-GISG meeting in Glasgow in October 1998 one of the workshops dealt with a two layer excess rating problem for General Liability business. The data were supplied by UK-insurers. The participants were predominately UK-actuaries. In the discussion important underwriting points were mentioned, points which had to be considered, however by nature difficult to quantify in the rate. On the other hand practically no time was devoted to discuss the chosen claim size distribution - in the actuarial case Pareto - or to the selection of the decisive parameter $\alpha$; see the Appendix below for some further thoughts. As these matters are of fundamental importance and will have a strong impact on the rates, particularly for the upper layer(s), I have been inspired to stimulate the research for analytical expressions suitable to approximate practical claim size distributions.

A Jury headed by Paul Embrechts and consisting also of Gary Patrik and Chris Stoop will judge the contributions. These should be mailed to Professor Paul Embrechts, Department of Mathematics, ETH-Zentrum, CH-8092 Zurich, Switzerland, before April 1, 2000. The prize is to be awarded at the year 2000 ASTIN meeting in Porto Cervo, Costa Smeralda, Italy (18-21 September, 2000).

The Jury will dispose of SEK $25^{\prime} 000$ and is free to give it to one or to divide it on several contributions.

\section{APPENDIX}

\section{Background}

Over a period of several decades, mathematical models for approximating observed data on claim sizes have included exponential, Pareto, American (or shifted) Pareto, lognormal, Weibull and - as some readers of this note may recall - exponential trinomial, etc. The number of parameters needed - not including a level factor - are respectively one, one, two, two, two and five.

In order to facilitate the discussion let us introduce the following notation: $H[R]=$ const $\cdot[1-F(R)]$ is the expected number of claims in excess of $R, \Pi[R]$ is the corresponding riskpremium for the layer $R$ to infinity, $m[R]$ is the expected average excess claim (i.e. the mean residual lifetime), and $\mu[R]$ the hazard rate (or extinction rate, or failure rate, or mortality rate of claims). Obviously

$$
\Pi[R]=H[R] \cdot m[R]
$$

and

$$
\mu[R]=-\frac{H^{\prime}[R]}{H[R]}=-\frac{d \ln H[R]}{d R}
$$


It is easily seen that

$$
\mu[R]=\frac{1+m^{\prime}[R]}{m[R]} .
$$

A study of the function $m[R]$ is to be found in Benktander-Segerdahl: On the analytical representation of claim distributions with special reference to excessof-loss reinsurance; the XVIth International Congress of Actuaries, Brussels 1960.

For Pareto $m[R]=\frac{R}{\alpha-1}$ and $\mu[R]=\frac{\alpha}{R}$ and $\ln \Pi[R]=$ const $-(\alpha-1) \ln R$. Pareto has in practical excess-of-loss-rating been widely used. This in spite of the fact that only moments up to an order below $\alpha$ exist. Further statistical work seems to indicate that often one needs models with $m^{\prime}[R]>0, m^{\prime \prime}[R]<0$, i.e. a strictly concave $m[R]$.

This has led to such modifications as:

BI defined by $m[R]=\frac{R}{a+2 b \ln R}$ which leads to

$$
\ln \Pi[R]=\mathrm{const}-a \ln R-b(\ln R)^{2}
$$

and

$$
\begin{aligned}
& \text { BII defined by } m[R]=\frac{R^{1-b}}{a} \text { which leads to } \\
& \qquad \Pi[R]=\text { const } \cdot e^{-\frac{u}{b} R^{h}}, 0<b<1, \ln \Pi[R]=\text { const }-\frac{a}{b} R^{b} .
\end{aligned}
$$

Observe that $b=1$ leads to Exponential and $b=0$ to Pareto.

For BII, $\mu[R]=\frac{1-b}{R}+\frac{a}{R^{1-h}}$. BII has been successfully used in practice and often gives an excellent description of large claims materials both from Fire and Motor. (Note from the Editor: These classes are now referred to as the Benktander I and II ciasses.)

\section{Challenge}

Study possible analytical expressions of $m[R]$ or $\mu[R]$ and calculate the corresponding function $H[R]$ with the restriction of having preferably two, and in any event not more than three required parameters. Test the calculated $H[R]$ on available extensive statistical data and calculate the goodness of fit. Indicate methods to determine the parameters.

GunNar BenkTANDER

Stockholm, 6 February 1999 